\title{
Multi-Purpose Road Network Modeling and Traffic Organization by Using Spatial Information Systems
}

\author{
Mojibulrahman Jami* \\ Faculty of Engineering, Herat University, Herat, Afghanistan \\ Email: jami.mojib856@gmail.com
}

How to cite this paper: Jami, M. (2019) Multi-Purpose Road Network Modeling and Traffic Organization by Using Spatial Information Systems. Journal of Geographic Information System, 11, 541-550. https://doi.org/10.4236/igis.2019.115033

Received: June 27, 2019

Accepted: October 11, 2019

Published: October 14, 2019

Copyright $\odot 2019$ by author(s) and Scientific Research Publishing Inc. This work is licensed under the Creative Commons Attribution International License (CC BY 4.0).

http://creativecommons.org/licenses/by/4.0/

\begin{abstract}
The first and most important step in designing a public transportation system is to determine the best way to move the fleet, which, in addition to providing the maximum demand for passengers, can be appropriate in terms of economic parameters and operating costs for the operating organization. The subject of this study is to determine the best route for starting the BRT line based on the eight objectives of the subset of the users' needs, route of the fleet movement and its traffic conditions and the conditions of the operating organization, between the Fixed Origin and destination. The Analytic Network Process has been used to prioritize the intended goals and determine the contribution of each to advance the issue. Replacing a hierarchical structure with a network structure in order to model the complex communication between decision elements is the advantage of the Analytic Network Process compared to the conventional methods of multi-criteria evaluation. Then, urban roads are categorized according to their role in relation to each of the problem parameters, and finally, the selected route is identified using the Arc GIS10.5 specialized software. The reached path (between the Qods terminal and the Khorram terminal) has been able to cover a population of 40,000 people, equivalent to 20 percent of the population of the study area. Considering a large number of parameters affecting in this problem, has created comprehensive result from the understanding and application of factors affecting the process of the problem, as opposed to most existing studies that use up to two or three goals.
\end{abstract}

\section{Keywords}

BRT, Network Analysis Process, Determination of the Best Route, Spatial Information System 


\section{Introduction}

A public rapid bus rapid transit system (BRT) is one of the bus systems, that has a higher capacity, better performance and more beautiful vista than the popular bus systems [1]. BRT system has the potential to attract passengers and thus has a significant impact on reducing urban traffic, as well as improving regional and environmental economics. Due to the high ability of the BRT vehicles to travel different paths, this system also has good flexibility [2]. The first and most important step in designing a public transportation system is determining the best route for the fleet to fly, in addition to providing maximum coverage for the costumer's demand, in terms of economic parameters and operating costs for the operating organization [3]. Meanwhile, there are many parameters that vary in different ways on the extent of pulling a new route for attracting passengers and meeting the needs of the operator organization [4]. The hierarchical analysis process is one of the most widely used multi-criteria assessment methods. The major limitation of AHP is that it does not consider the interdependencies between decision elements, the dependence of criteria, sub-criteria, and options. It also assumes the relationship between decision elements hierarchically and unilaterally. However, in the method of the network analysis process, the complex communication between the decision elements is to be considered by replacing the hierarchical structure with the network structure [5]. Finally, considering that the origin and destination of the new fixed line are considered, the best route from the passages was obtained with the highest utility index in the GIS environment. In the area of transportation planning and decision making, a variety of decision-making methods, as well as geographic information systems, have been widely used by various researchers.

Yedla \& Shresta (2003) evaluated and selected the proposed transportation options in Delhi using hierarchical analysis method [6]. They assessed for this purpose three common transportation options in Delhi, namely two-wheeled engines, CNG cars and CNG buses, in terms of three-small-scale fuel economy, reduced environmental pollution, and Cost of operation. Also, three qualitative criteria assess the availability of technology, compliance with the environment and implementation barriers. Tzeng et al. (2005) used multi-criteria hierarchical analysis and topsis analysis methods for evaluating buses with different fuels for use in public transport in various urban areas of Taiwan [7]. Ciaffi et al. (2012) in a research paper titled "Providing a New Method for Designing a Public Transportation Network" addressed the issue of designing and routing bus lines. The main purpose of their research was to balance the users in the network, taking into account constraints such as the capacity of the fleet and the length of the route [8]. Tlili et al. (2013), in his research entitled Integration of Geographic Information Systems (GIS) and multi-criteria evaluation methods, presented a method for solving the routing problem with the goal of a minimum total cost for the fleet [9].

The present study is to determine the best route among the eligible initial 
passages for crossing the BRT line in Khomeini-Shahr city, Isfahan, with regard to traffic, infrastructure, social and economic indicators. Indicators affecting the problem are obtained after a library study and consultation with experts based on the conditions of the study area. By choosing effective parameters based on the fleet movement and traffic conditions governing it, as well as maximizing the concerns of users of the system, as far as possible, all the angles of choosing an optimal route were seen based on the comprehensiveness and multi-dimensionality of the criteria intended. Obviously, each of these criteria does not have the same role in the problem, and each one can take different weights. Therefore, a multi-criteria evaluation method is used to determine the impact of each of the indicators considered.

\section{Explaining the Model and Pattern Chosen for the Parameters Considered}

Initially, the problem is converted into a network structure in which the nodes act as clusters [10]. Then, the criteria and sub-criteria are considered to be used to locate the path of the BRT line in the studied area. These criteria are obtained after studying the library and articles related to the research, as well as consulting with the experts of the mentioned area and based on the conditions and characteristics of the city of Khomeini_Shahr.

\subsection{Create a Binary Comparison Matrix and Identify Priority Vectors}

At this stage, the matrices of the main criteria, the dependence of the main criteria to each other, the matrix of comparative sub-criteria, and the sub-criteria dependence on each other are formed [11]. A questionnaire was used by some university professors (7 people) and some municipal officials and bus organizations (8 people). Then, the matrix elements of the binary comparison of criteria and sub-criteria were derived from the mean of group views (Table 1).

\subsection{Create Super Matrix}

In order to achieve the overall priority in a system with interactions, internal priority vectors are inserted into the appropriate columns of a matrix. As a result, a super matrix (a classified matrix) was obtained, each section showing the relationship between two clusters in a system. This type of matrix is called the primitive super matrix. By replacing the vector of internal priorities (coefficients of importance), the elements and clusters of this matrix are completed. In the next step, the weighted super matrix is calculated by normalizing non-weighted

Table 1. Binary comparison of internal dependencies of main criteria.

\begin{tabular}{ccc}
\hline Users & Path & \\
\hline $\mathbf{0 . 1 8 5}$ & 1.0 & Path \\
1.0 & 5.4 & Users \\
\hline
\end{tabular}


super matrix. In the final step, the limited super matrix can power all the weighted super matrix elements until divergence is achieved. In other words, all elements of the super matrix are similar through repetition (Table 2) [12].

\subsection{Determine the Rating of Each of the Passages}

The following equation was used to determine the rating of each of the corresponding passages:

$$
D_{i}=\sum_{j=1}^{J} W_{i} * E_{i j}
$$

where $D_{i}$ is the utility index $i, W_{i}$ is the relative importance of the sub_criteria $j$ (extracted from the limited super matrix) and $E_{i j}$ is score $i$ from the sub_criteria $j$.

\subsection{The Population Covered by Each Street}

Population density has a significant impact on the demand for public transportation, so that in densely populated areas, if there is a high level of service, there is an increase in demand for the use of the bus network [13]. By forming a pedestrian network that includes all the streets, alleys and roads that can be crossed by pedestrians, and performing an analysis of the range of services can estimate the population covered by each of the stations located at a radius of 400 meters of that station resident. For inter-urban areas, the distance between the two stations was 400 to 500 meters. To cover the population in the streets in question, the overlapping of the population of each of the existing stations of a street was completely prevented from overlapping the population in adjacent streets as far as possible (Table 3 ).

Table 2. Binary comparison of internal dependencies of sub-criteria.

\begin{tabular}{ccccc}
\hline Population & Landuse & Passengers & Density & Link length \\
\hline Landuse & 1.0 & 3.5 & 4.5 & 4.5 \\
Passengers & 0.286 & 1.0 & 3.0 & 3.0 \\
Density & 0.222 & 0.333 & 1.0 & 2.5 \\
Link length & 0.222 & 0.333 & 0.4 & 1.0 \\
\hline
\end{tabular}

Table 3. The weight of each parameter group in the service level.

\begin{tabular}{cccccccc}
\hline Weight & Service level & A & B & C & D & E & F \\
\hline 0.421 & A & 1.0 & 3.0 & 4.0 & 6.0 & 7.0 & $\mathbf{9 . 0}$ \\
0.256 & B & 0.333 & 1.0 & 3.0 & 5.0 & 6.0 & $\mathbf{8 . 0}$ \\
0.163 & C & 0.25 & 0.333 & 1.0 & 4.0 & 5.0 & $\mathbf{7 . 0}$ \\
0.09 & D & 0.167 & 0.2 & 0.25 & 1.0 & 4.0 & $\mathbf{5 . 0}$ \\
0.046 & E & 0.143 & 0.167 & 0.2 & 0.25 & 1.0 & $\mathbf{3 . 0}$ \\
0.026 & F & 0.111 & 0.125 & 0.143 & 0.2 & 0.333 & $\mathbf{1 . 0}$ \\
\hline
\end{tabular}




\subsection{Bus Station Passengers}

Considering the travel of individuals and the coverage of this trip by any public transportation line is much more important than considering the population covered. Because the population has the potential to travel with the public vehicle, this potential does not always lead to travel [14]. In order to use this criterion, passenger information was used for ordinary bus lines. The number of passengers traveling at different stations by bus fleet could be an appropriate approximation of the demand for the use of the BTR system [15]. Thus, using the Automatic Fare Collection system data was obtained by the information of passengers boarded and discharged at each station. Finally, the information was collected for stations on a street and added to the corresponding street. The bus lines in the studied area network are equipped with the AFC system, and passenger fares are recorded in this system.

Type of Passage and Passing Width of Each Passage

Road traffic on the boulevard is more secure because of the separation of passageways, and it has the ability to pass traffic faster. Also, it is easier to construct a special line for passing the BRT fleet in passages with higher line widths [16].

\subsection{Number of Intersections per Corridor}

The presence of an intersection, including the square, crossroads, etc., in the direction of the movement of the system of BTR leads to a change in its mode of movement from a separate mode (the path that is separated along its path by a variety of obstacles from the traffic flow) into a mixed state (route Which is located on the street and in direct encounter with other vehicles in the traffic flow), which is a disadvantage for the network [17].

\subsection{Service Level}

The service level represents the status of road traffic from a qualitative perspective, and varies from the best position to the extent that drivers stop and move [18]. In this research, assuming that the existence of the BRT line in high-density routes (with a weaker service level) is of higher priority, service level F receives the highest priority over other levels. To define the service level of each route involved in the analysis, the HCM standard was used. For this purpose, it is necessary to calculate the average speed of vehicles in each of the urban routes. So, at the first stage, the time of travel of vehicles at peak hours was taken on each route. To collect time travel information and calculate the speed and level of service, a car was used that moves at a speed equivalent to the average traffic flow of the evening traffic $(19-22 \mathrm{pm})$. For each route at least twice the travel time was taken and its average was determined as the time of the journey of that route.

\subsection{Land Use}

The starting point for any public transportation network should be a land use pattern because different land patterns can be highly effective in creating traffic 
[19]. Full coordination between urban development and the design of public transportation networks is often the only way to achieve high performance, both in land use activities and in the operation of the transportation system [20]. The area of land use around each path was calculated individually in GIS. These land uses include commercial, residential, cultural, educational, health, medical, administrative, recreational, sports, green spaces, and parking (Table $4 \&$ Table 5).

\subsection{Access Density}

The purpose of this parameter is to gain access to each street and its role in guiding passengers to the use of the public transportation fleet, as well as the impact of each of these accesses on the traffic volume and safety of the route in question. This item is considered less in network design. However, the access density parameter can play an important role in the comfort and attraction of passengers [21].

\section{Construction Cost per Connection Length}

The path length should be kept as low as possible, which would reduce operational costs [22]. The lowest path length and the greatest coverage of demand

Table 4. The weight of each land use group.

\begin{tabular}{ccccccccc}
\hline Weight & Landuse & Commercial & Residential & Cultural & Health & Official & Sports & Parking \\
\hline $\mathbf{0 . 1 9 5}$ & Commercial & 1.0 & 0.25 & 3.0 & 5.0 & 2.0 & 5.0 & 6.0 \\
$\mathbf{0 . 4 0 4}$ & Residential & 4.0 & 1.0 & 5.0 & 7.0 & 4.0 & 7.0 & 8.0 \\
$\mathbf{0 . 0 9 5}$ & Cultural & 0.333 & 0.2 & 1.0 & 3.0 & 0.25 & 3.0 & 5.0 \\
$\mathbf{0 . 0 5 7}$ & Health & 0.2 & 0.143 & 0.333 & 1.0 & 0.2 & 5.0 & 6.0 \\
$\mathbf{0 . 1 7 6}$ & Official & 0.5 & 0.25 & 4.0 & 5.0 & 1.0 & 5.0 & 6.0 \\
$\mathbf{0 . 0 4 8}$ & Sports & 0.2 & 0.143 & 0.333 & 0.5 & 0.2 & 1.0 & 4.0 \\
$\mathbf{0 . 0 2 5}$ & Parking & 0.167 & 0.125 & 0.2 & 0.25 & 0.167 & 0.25 & 1.0 \\
\hline
\end{tabular}

Table 5. The weight of the classes of cultural, residential and commercial landuse.

\begin{tabular}{cccccc}
\hline Cultural & Weight & Residental & Weight & Commercial & Weight \\
\hline $0-500$ & 0.01 & $0-1500$ & 0.012 & $0-1500$ & $\mathbf{0 . 0 1 2}$ \\
$500-2000$ & 0.101 & $1500-7000$ & 0.028 & $1500-7000$ & $\mathbf{0 . 0 3 7}$ \\
$2000-4000$ & 0.131 & $7000-15,000$ & 0.063 & $7000-15,000$ & $\mathbf{0 . 0 6 3}$ \\
$4000-6000$ & 0.155 & $15,000-25,000$ & 0.087 & $15,000-25,000$ & $\mathbf{0 . 0 8 8}$ \\
$6000-8000$ & 0.181 & $25,000-30000$ & 0.114 & $25,000-30000$ & $\mathbf{0 . 1 1 3}$ \\
$8000-10,000$ & 0.206 & $30,000-35,000$ & 0.142 & $30,000-35,000$ & $\mathbf{0 . 1 3 8}$ \\
$10,000-12,000$ & - & $35,000-40,000$ & 0.165 & $35,000-40,000$ & $\mathbf{0 . 1 6 3}$ \\
$12,000-14,000$ & - & $40,000-50,000$ & 0.189 & $40,000-50,000$ & $\mathbf{0 . 1 8 7}$ \\
$14,000-18,000$ & 0.216 & $50,000-60,000$ & 0.199 & $50,000-60,000$ & $\mathbf{0 . 1 9 9}$ \\
\hline
\end{tabular}


can be considered as one of the most important goals in providing bus services [23].

After determining the utility index of each of the routes under consideration, using the ArcGIS software, the best route was obtained based on the highest calculated indices. Figure 1 shows the configuration of the desired utility for each of the selected paths.

The green color is devoted to those paths that have a utility index of 0.1556 to 0.2078 (highest), blue is from 0.1036 to 0.1556 , and the red color is from 0.1036 to 0.0516 (the lowest index is obtained). In other words, the priority of choosing the route as part of the desired route is first with green and then blue. Red lines are not used because of low scores. Considering the limited budget of the bus organization to build the BRT route in the area, finding the most efficient corridor is very important. The specified route with a length of about $8 \mathrm{~km}$ and a population coverage of 40,000 people ( $20 \%$ of the region's population) are able to cover the maximum demand for passengers. This route is between the Qods terminal and the Khorram terminal. It is worth noting that among the target parameters, the passengers in each direction and the population covered by each street, were identified as the most important parameters of the formation of the new network in the study area.

The station element is the first point of communication between people and the BTR system. For this reason, the location of the station is very important from the perspective of the researcher. In the present study, the location of the stations was chosen to minimize the time of the passenger's pedestrian and boarding and reduce travel time. Given the traffic situation, the passageway, the speed at the route, and the Khomeini-Shahr population centers, the distance between the stations was between 300 and 1000 meters; however, in the arterial streets at least the distance and in the non-arterial streets maximum distance selected. In total, the total number of stations between the two terminals, $8 \mathrm{~km}$ away from each other, is 12 stations.

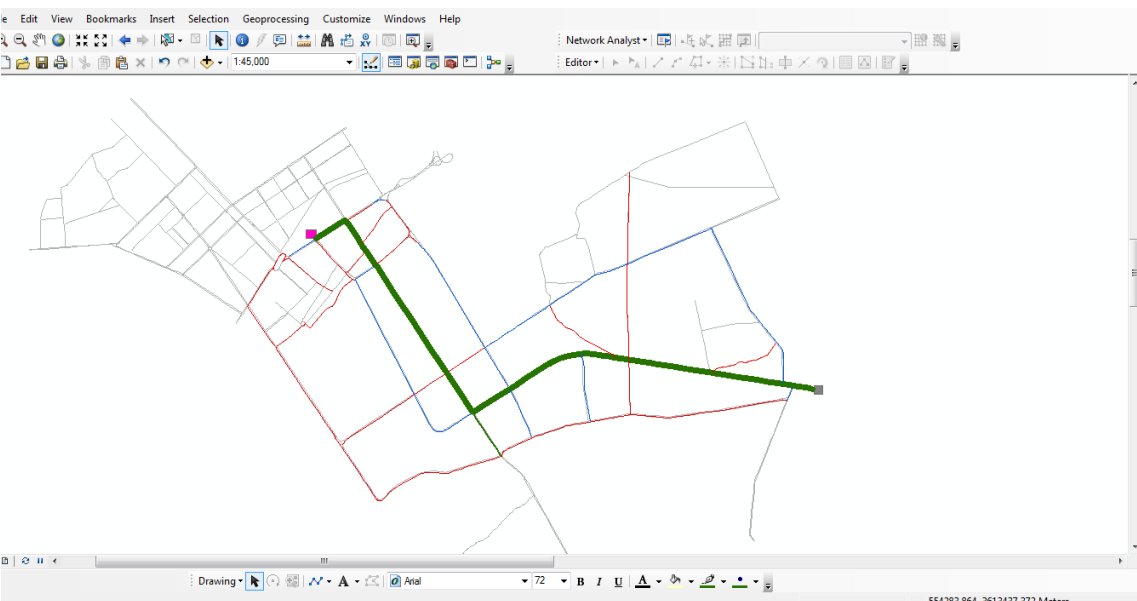

Figure 1. The best route for the BRT between the Qods terminal and the Khorram terminal. 


\section{Discussion}

A high-speed bus system is a kind of street transport system equipped with modern technologies that have the precision and speed of the rail transport system and the flexibility of the bus transport at the same time. The benefits of this system are becoming widespread in the world, and currently the UK has the largest number of buses of this type. Accordingly, and given the positive experience of using the BRT system in Iran's metropolises especially in Tehran, the researcher sought to design the BTR route for Khomeini-Shahr. The main advantages of this system in Khomeini-Shahr city can be counted as follows:

1) Lower waiting time at stations;

2) Precise information to passengers at the station and bus with appropriate timetable;

3) Get tickets before the bus arrives and remove the direct relationship between the driver and the passenger;

4) Intelligent allocation to buses: With this system, special buses can be provided for intermediate stations or stations that are more expensive at the specific time of day than they require to use the route, allocating Gave;

5) Establish complementary systems to reduce the special passenger's load;

6) Installing city guide boards at the beginning of the routes that have changed the role of access through the creation of the BRT;

7) Ease of use of physical-motorized handicapped;

8) The existence of a single control center that increases direct productivity;

9) Reduce air pollution and reduce traffic.

\section{Conclusions}

In general, according to studies, the establishment of each urban element in a particular space-spatial position of the city level has been subject to principles, rules, mechanisms and mechanisms that, if observed, are to the success and effectiveness of that element in the site. It will be clear and otherwise there will be a lot of problems. BRT routing has a huge impact on reducing costs and facilitating the passage of citizens by public transportation, according to spatial information and citizen needs assessment. For this reason, it is one of the important and effective stages of public transport projects. One of the challenges of urban planners in urban spaces is the design and routing of bus routes. In Khomeini Shahr, the unsustainability of the bus route and the lack of a BRT system have caused problems for citizens such as increasing the length and time of travel, congestion, lack of access to administrative, commercial, educational, facilities and equipment.

In order to better route in the future in the range some suggestions have been made:

- Understanding the spatial distribution of bus stations, updating statistics and information on urban utilities;

- Use of new information and management systems in routing; 
- Developing routes especially in areas that a city is crowded because of the cost of travel and easy access to home and work.

\section{Conflicts of Interest}

The author declares no conflicts of interest regarding the publication of this paper.

\section{References}

[1] Betancourt, R.M., Galvis, B., Rincon-Riveros, J.M., Rincon-Caro, M.A., Rodrigues-Valencia, A. and Sarmiento, O.L. (2019) Personal Exposure to Air Pollutants in a Bus Rapid Transit Systems: Impact of Fleet Age and Emission Standard. Atmospheric Environment, 202, 117-127. https://doi.org/10.1016/j.atmosenv.2019.01.026

[2] Poku-Boansi, M. and Marsden, G. (2018) Bus Rapid Transit System as a Governance Reform Project. Journal of Transport Geography, 70, 193-202. https://doi.org/10.1016/j.jtrangeo.2018.06.005

[3] Ruano-Daza, E., Cobos, C., Torres-Jimenez, J., Mendoza, M. and Paz, A. (2018) A Multiobjective Bilevel Approach Based on Global Best Harmony Search for Defining Optimal Routes and Frequencies for Bus Rapid Transit Systems. Applied Soft Computing, 67, 567-583. https://doi.org/10.1016/j.asoc.2018.03.026

[4] KianiMavi, R., Zarbakhshnia, N. and Khazraei, A. (2018) Bus Rapid Transit (BRT): A Simulation and Multi Criteria Decision Making (MCDM) Approach. Transport Policy, 72, 187-197. https://doi.org/10.1016/j.tranpol.2018.03.010

[5] Gorener, A. (2012) Comparing AHP and ANP: An Application of Strategic Decisions Making in a Manufacturing Company. International Journal of Business and Social Science, 3, 194-208.

[6] Yelda, S. and Shrestha, R.M. (2003) Multi-Criteria Approach for the Selection of Alternative Options for Environmentally Sustainable Transport System in Dehli. Transportation Research Part A, 37, 717-729. https://doi.org/10.1016/S0965-8564(03)00027-2

[7] Tzeng, G.H., Lin, C.W. and Opricovic, S. (2005) Multi-Criteria Analysis of Alternative Fuel Buses for Public Transportation. Energy Policy, 33, 1373-1383. https://doi.org/10.1016/j.enpol.2003.12.014

[8] Ciaffi, F., Cipriani, E. and Petrelli, M. (2012) Feeder Bus Network Design Problem: A New Metaheuristic Procedure and Real Size Applications. Procedia, 54, 798-807. https://doi.org/10.1016/j.sbspro.2012.09.796

[9] Tlili, T., Faiz, S. and Krichen, S. (2013) Integration of GIS and Optimization Routines for the Vehicle Routing Problem. International Journal of Chaos, Control, Modelling and Simulation, 2, 9-17.

[10] Rodrigue, J.P. and Ducruet, C. (2017) The Geography of Transport System. 14th Edition, Routledge, New York, 440.

[11] Kou, G., Ergu, D., Lin, C. and Chen, Y. (2016) Pairwise Comparison Matrix in Multiple Criteria Decision Making. Technological and Economic Development of Economy, 22, 738-765. https://doi.org/10.3846/20294913.2016.1210694 http://www.tandfonline.com/loi/tted21

[12] Petersen, K.B. and Pedersen, M.S. (2012) The Matrix Cookbook. 72. http://matrixcookbook.com 
[13] Ceder, A. (2007) Public Transit Planning and Operation: Theory, Modeling and Practice. Elsevier, Butterworth-Heinemann, Oxford, 640 p. https://doi.org/10.1201/b12853

[14] Zak, J. and Hadas, Y. (2018) Advanced Concepts, Methodologies, and Technologies for Transportation and Logistics. Springer International Publishing, New York, 470 p. https://doi.org/10.1007/978-3-319-57105-8

[15] Loh, Z.X.K. (2014) Factors Influencing Bus Network Design. Massachusetts Institute of Technology, Cambridge, MA, $79 \mathrm{p}$.

[16] Ajayi, A.P. (2017) Assessment of the Influence of Lagos Bus Rapid Transit Scheme (BRT-Lite) on Road Traffic Crashes (RTC) on Lagos Mainland-Island Corridor. The Open Transportation Journal, 11, 102-109. https://doi.org/10.2174/1874447801711010102

[17] Toma, S, Fukuda, A., Hashino, Y. and Satiennam, T. (2012) Analysis of BRT Priority Signal Control System Implementation in Major Intersections of Khon Kaen City. 5st Atrans Symposyum, 102-107.

[18] Carey, G.N. (2002) Applicability of Bus Rapid Transit to Corridors with Intermediate Levels of Transit Demand. Journal of Public Transportation, 5, 97-113. https://doi.org/10.5038/2375-0901.5.2.5

[19] Deng, T. and Nelson, J.D. (2010) The Impact of Bus Rapid Transit on Land Development: A Case Study of Beijing, China. International Journal of Humanities and Social Sciences, 4, 1169-1179.

[20] Johnson, A. (2003) Bus Transit and Landuse: Illuminating the Interaction. Journal of Public Transportation, 6, 21-39. https://doi.org/10.5038/2375-0901.6.4.2

[21] Mohammad-Beigi, H., Nouri, J. and Liaghati, H. (2015) Strategic Analysis of Bus Transit System in Improvement of Public Transportation: Case of Tehran, Iran. Modern Applied Science, 9, 169-178. https://doi.org/10.5539/mas.v9n9p169

[22] Pedro, M.J.G. and Macario, R. (2016) A Review of General Practice in Contracting Public Transport Services and Transfer to BRT Systems. Research in Transportation Economics, 59, 94-106. https://doi.org/10.1016/j.retrec.2016.07.010

[23] Wijaya, S., Imran, M. and McNeill, J. (2017) Multi Level Policy Tensions in Bus Rapid Transit (BRT) Development in Low-Income Asian Cities. Transportation Research Procedia, 25, 5104-5120. https://doi.org/10.1016/j.trpro.2018.02.040 